\title{
Synthesis and Properties of a Novel Highly Thermal Stable N-propargyl Monomer Containing Benzoxazole Ring
}

Guang Yang ${ }^{1}$, Chengbo Wang ${ }^{1}$, Chao Liu ${ }^{1}$, Zhiyong Yang ${ }^{1,2}$, Xianghui Hou ${ }^{3}$

${ }^{1}$ School of Material Science and Engineering, Beihang University, Beijing100191, China

${ }^{2}$ Center of Structure Composite Materials, Aerospace Research Institute of Materials \& Processing Technology, Beijing100076, China

${ }^{3}$ Faculty of Engineering, University of Nottingham, Nottingham, NG7 2RD, UK

\section{Corresponding author:}

Guang Yang, Key Laboratory of Aerospace Advanced Materials and Performance (Beihang University), Ministry of Education, School of Materials Science and Engineering, Beihang University, Beijing, 100191, China.

E-mail: yangguang@buaa.edu.cn

\begin{abstract}
:
A novel highly thermal stable propargyl functional compound containing benzoxazole ring, N, N, N', N'-tetra propargyl-5-amino-2-(p-aminophenyl) benzoxazole (TPAPB), was proposed and synthesized using phase-transfer catalytic method. The cure behavior of TPAPB was investigated by non-isothermal differential scanning calorimetry analysis (DSC). The solubility and rheological properties of TPAPB, as well as its broad temperature window from $130{ }^{\circ} \mathrm{C}$ to $200{ }^{\circ} \mathrm{C}$ with low viscosity, offered excellent processability for TPAPB to be used as a potential monomer of thermosetting polymer resin. It was found that the glass transition
\end{abstract}


temperature $\left(T_{g}\right)$ of cured TPAPB was $359^{\circ} \mathrm{C}$, and the temperature of $5 \%$ weight loss $\left(\mathrm{T}_{d 5}\right)$ was $418{ }^{\circ} \mathrm{C}$ in argon with the char residue up to $70 \%$ at $700{ }^{\circ} \mathrm{C}$. The polymerized resin exhibited high heat resistance and thermal stability, together with its processability, making it good candidate as highly heat-resistant polymer matrix for advanced composite applications.

\section{Keywords}

Propargyl, Benzoxazole, Thermal stability, Phase-transfer catalysis, Purification 


\section{Instruction}

Resins terminated with acetylene ${ }^{1,2}$ or phenylacetylene ${ }^{3,4}$ have a long shelf life and their cured products have excellent solvent resistance and favorable combination of physical and mechanical properties at high temperature. However, the small processing window is a major concern on processability of acetylene-terminated resins and the high cure temperature makes phenylacetylene-terminated resins less processable. ${ }^{5}$ Moreover, the high material cost also restricts their applications. ${ }^{6}$ In contrast to terminal acetylene or phenylacetylene functional resins, propargyl derivatives are much attractive for their easiness of synthesis and polymerization. ${ }^{7}$ Furthermore, excellent thermal and mechanical properties facilitate the resins suitable for composites, ${ }^{8}$ adhesives ${ }^{9}$ and special coatings. ${ }^{10}$

Many aromatic heterocyclic moieties, such as pyridine, ${ }^{11}$ benzothiazole, ${ }^{12}$ benzoxazole ${ }^{13}$ and benzimidazole,${ }^{14}$ can improve thermal and mechanical properties of resins. Significant efforts have been paid on introducing an aromatic benzoxazole ${ }^{15}$ or benzobisxazole ${ }^{16}$ unit into the main chain of the polymer to improve thermal stabilities. In addition, most of the studies have been devoted to synthesis and polymerization of a few propargyl ether systems. ${ }^{17,}{ }^{18}$ Liu et al. ${ }^{19}$ introduced benzimidazole moieties into the backbone of polyimide and the co-PI fibers exhibit extremely high tensile strength and initial modulus along with good thermal properties. Wang et al. ${ }^{20}$ synthesized 
high-temperature multiple-shape memory poly(benzoxazole-co-imide)s with superior thermal stability. The polymer possessed high tensile strength and good elongation.

However, one of the critical drawbacks of benzoxazole is its poor solubility in organic solutions due to its stiff structure, which is detrimental to its processability. ${ }^{21}$ From our previous results, the introduction of propargyl would enhance the solubility of highly heat-resistant resins and reduce the melting point of the monomers, ${ }^{22,23}$ which is beneficial to their processing.

To achieve highly thermal stability, the present work aims on the synthesis of a novel monomer with a broad processing window. A propargyl-functional compound containing benzoxazole ring, N, N, N', N'-tetra propargyl-5-amino-2-(p-aminophenyl) benzoxazole (TPAPB) has been synthesized by phase-transfer catalysis method. The investigation involved the synthesis and characterization of TPAPB as well as the optimization of the reaction conditions. The properties of TPAPB and its polymerized product were also studied.

\section{Experimental}

\section{Materials}

Dichloromethane (AR, Beijing chemical works China), propargyl bromide (CP, Yangcheng Longsheng fine chemical works China), tetrabutyl-ammonium bromide (AR, Tianjin fine chemicals institute China), 2,4-diamino-phenol hydrochloride (Beijing chemical regent company China, recrystallized before further use), p-aminobenzoic acid 
(AR, Beijing Yili fine chemicals Co. Ltd China), phosphoric acid (AR 85\%, Beijing chemical regent company China), stannous chloride (AR, Shantou Xilong Chemical Works China).

\section{Measurements}

${ }^{1} \mathrm{H}$ NMR spectrum was recorded on a $\mathrm{FX}-90 \mathrm{Q} 300(300 \mathrm{MHz})$ with $\mathrm{CDCl}_{3}$ as solvent. FT-IR spectrum was obtained from a Nicolet NEXUS-470 FT-IR spectrometer. Thermal analysis was performed on Differential Scanning Calorimetry (DSC) and Thermal Gravimetric Analysis (TGA) was conducted with a NETZSCH STA449C DSC-TGA analyzer, at a heating rate of $20{ }^{\circ} \mathrm{C} / \mathrm{min}$ under argon atmosphere. The rheological characteristics of TPAPB were carried out on an Advanced Rheometric Expansion System rheometer under nitrogen atmosphere at a heating rate of $5{ }^{\circ} \mathrm{C} / \mathrm{min}$ in a frequency of $1 \mathrm{~Hz}$. The melting point was measured by an X-5 microscopic melting point apparatus.

\section{Synthesis of 5-amino-2-(p-aminophenyl) benzoxazole}

The reaction scheme for the synthesis of 5-amino-2-(p-aminophenyl) benzoxazole by dehydration-condensation reaction ${ }^{24}$ was shown in Scheme 1.

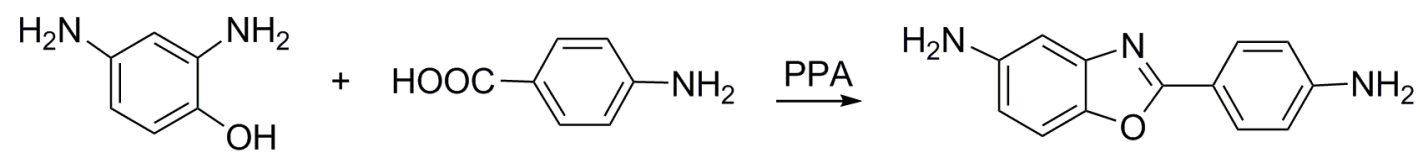

Scheme 1. Synthesis of 5-amino-2-(p-aminophenyl) benzoxazole 
First, polyphosporic acid was prepared as follows. Phosphorus pentoxide (60 g, $0.42 \mathrm{~mol}$ ) was added in a $250 \mathrm{~mL}$ three-necked, round flask with a nitrogen gas inlet tube. Then $85 \%$ phosphoric acid was injected into the reaction flask within $0.5 \mathrm{~h}$, the flask was shaken so that the phosphorus pentoxide could be completely dissolved in phosphoric acid. The reaction mixture was slowly heated to $140{ }^{\circ} \mathrm{C}$, stirred continuously and kept at this temperature for $4 \mathrm{~h}$. When the mixture changed to transparent, polyphosporic acid was obtained and then cooled to $60{ }^{\circ} \mathrm{C}$. 2, 4-diamino-phenol hydrochloride $(9.85 \mathrm{~g}, 0.05 \mathrm{~mol}), \mathrm{p}$-amino-benzoic acid $(7.54 \mathrm{~g}, 0.055 \mathrm{~mol})$ and stannous chloride $(0.3 \mathrm{~g}, 1.58 \mathrm{mmol})$ were added to the flask respectively. The reaction was processed by vacuum pumping intermittently to remove hydrogen chloride in the temperature range of $60-110{ }^{\circ} \mathrm{C}$ for $12 \mathrm{~h}$, and the reaction mixture was slowly heated to $200{ }^{\circ} \mathrm{C}$ for $5 \mathrm{~h}$. Then the reaction mixture was cooled to $100{ }^{\circ} \mathrm{C}$ and poured into the mixture of ice and water. The sediment product was washed, neutralized by $10 \%$ sodium carbonate solution, repeatedly washed, air pump filtered, and dried in vacuum. Finally, a kind of yellow solid powder was obtained. Yield: 9.4 g, 83.6\%. m.p.:230 $231{ }^{\circ} \mathrm{C}$. Elemental analysis, measured value (calculated value), \%: C 68.87 (69.31); H 4.92(4.92); N 18.44 (18.66). ${ }^{1} \mathrm{H}-\mathrm{NMR}\left(\mathrm{DMSO}_{2}\right.$-d6, 300MHz), $\delta: 7.284,7.313$ (m, 1H, Ar-H); 6.796 (m, 1H, Ar-H); 7.757, 7.786 (d, 2H, J =6 Hz); 5.643, (s, 4H, $\left.\mathrm{NH}_{2} \times 2\right)$. IR (KBr), v, cm ${ }^{-1}: 3394,3323,1610,1579,1498,1268,950$. 
Synthesis of N, N, N', N'tetra propargyl-5-amino-2-(p-aminophenyl) benzoxazole (TPAPB)

TPAPB was synthesized from 5-amino-2-(p-aminophenyl) benzoxazole and propargyl bromide by phase-transfer catalysis. The reaction scheme for synthesizing TPAPB was shown in Scheme 2.

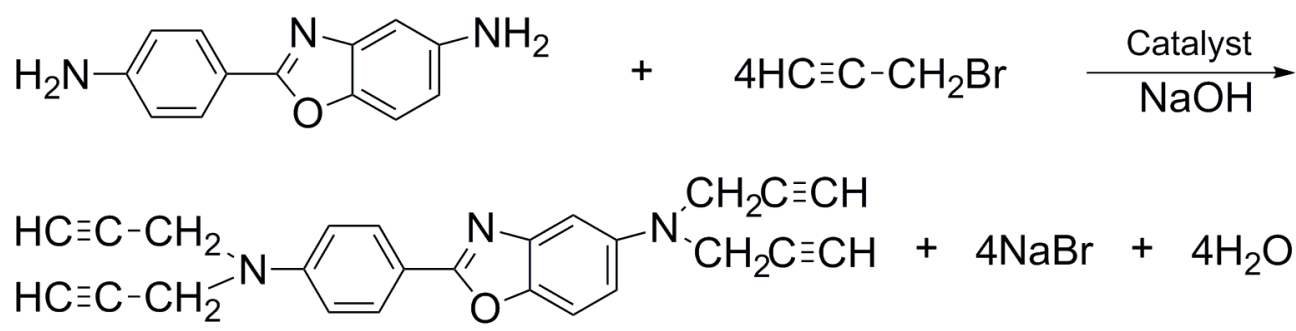

Scheme 2. Synthesis of TPAPB

5-amino-2-(p-aminophenyl) benzoxazole, $\mathrm{NaOH}$, deionized water, solvent and phase transfer agent were poured into a $100 \mathrm{~mL}$ three-neck bottom flask with a nitrogen gas inlet tube. Then propargyl bromide was added dropwise at $30{ }^{\circ} \mathrm{C}$ within $1 \mathrm{~h}$ under intensive stirring. The reaction mixture was continuously stirred at $20-50{ }^{\circ} \mathrm{C}$ for several hours. In each experiment, the amount of propargyl bromide, 5-amino-2-(p-aminophenyl) benzoxazole, $\mathrm{NaOH}$, deionized water and solvent was 8.33 $\mathrm{g}(0.07 \mathrm{~mol}), 2.25 \mathrm{~g}(0.01 \mathrm{~mol}), 1.6 \mathrm{~g}(0.04 \mathrm{~mol}), 5.74 \mathrm{~g}$, and $5.74 \mathrm{~g}$, respectively. The different reaction conditions for synthesis of TPAPB were shown in Table I. On the completion of the reaction, the solvent layer was separated from aqueous layer and washed with deionized water three times. 
Table I. Different reaction conditions for the synthesis of TPAPB

\begin{tabular}{|c|c|c|c|c|c|c|c|}
\hline No. & Solvent & $\begin{array}{c}\text { Temp. } \\
\left({ }^{\circ} \mathrm{C}\right)\end{array}$ & $\begin{array}{l}\text { Alkali } \\
\text { liquor }\end{array}$ & $\begin{array}{l}\text { Phase } \\
\text { transfer } \\
\text { agent }\end{array}$ & $\begin{array}{c}\text { Amount of } \\
\text { phase } \\
\text { transfer } \\
\text { agent }^{\mathrm{b}}(\%)\end{array}$ & $\begin{array}{l}\text { Time } \\
\text { (h) }\end{array}$ & $\begin{array}{c}\text { Yield } \\
(\%)\end{array}$ \\
\hline 1 & dichloromethane & 20 & $\mathrm{NaOH}$ & $\mathrm{TBAB}^{\mathrm{a}}$ & 4.9 & 16 & 0 \\
\hline 2 & dichloromethane & 50 & $\mathrm{NaOH}$ & TBAB & 4.9 & 11 & 95.3 \\
\hline 3 & $\mathrm{DMF}$ & 70 & $\mathrm{NaOH}$ & - & - & 11 & 62.7 \\
\hline 4 & dichloromethane & 50 & $\mathrm{NaOH}$ & TBAB & 2.5 & 11 & 54.1 \\
\hline 5 & dichloroethane & 70 & $\mathrm{~K}_{2} \mathrm{CO}_{3}$ & TBAB & 4.9 & 11 & 66.9 \\
\hline 6 & dichloroethane & 70 & $\mathrm{NaOH}$ & TBAB & 4.9 & 11 & 82.1 \\
\hline 7 & dichloromethane & 50 & $\mathrm{~K}_{2} \mathrm{CO}_{3}$ & TBAB & 4.9 & 11 & 49.5 \\
\hline 8 & dichloromethane & 50 & $\mathrm{KOH}$ & TBAB & 4.9 & 11 & 72.3 \\
\hline
\end{tabular}

a Tetrabutyl-ammonium bromide was short for TBAB.

b The amount of phase transfer agent was accounted for the amount of 5-amino-2-(p-aminophenyl)benzoxazole(mole fraction)

After distillation, a solid product was obtained, which was subjected to further purification and separation to obtain pure compound. Finally, a yellow solid powder was obtained. FT-IR and ${ }^{1} \mathrm{H}-\mathrm{NMR}$ spectra were employed to determine the structure of the product.

\section{Curing of TPAPB}

The curing was carried out by heating the monomer in air by the following gradually heating procedure: $180{ }^{\circ} \mathrm{C} / 1 \mathrm{~h}, 200{ }^{\circ} \mathrm{C} / 2 \mathrm{~h}, 230{ }^{\circ} \mathrm{C} / 2 \mathrm{~h}$ and $250{ }^{\circ} \mathrm{C} / 10 \mathrm{~h}$. Thereafter, the resin was post cured at $300{ }^{\circ} \mathrm{C}$ for $1 \mathrm{~h}$. A black polymerized product was obtained. 


\section{Results and discussion}

\section{Synthetic reaction conditions of TPAPB}

From the principle of phase-transfer catalysis, synthesis of TPAPB is a nucleophilic substitution reaction and 5-amino-2-(p-aminophenyl) benzoxazole is the nucleophile. To establish the optimum reaction conditions according to the yield of product, different methods have been applied to synthesize TPAPB by changing reaction conditions.

There are many clear advantages of phase-transfer catalytic method compared with other organic synthesis methods. It can reduce reaction time and lower reaction temperature. Moreover, the degree of reactions can be significantly increased because the catalysis can assist reactants to contact mutually. The reaction conditions of experiment No.3 to No.6 were same except the solvent and phase transfer agent. Owing to phase transfer agent, the yield of experiment No.6 (82.1\%) was much improved from that of No.3 (62.7\%).

Inherent characteristic of phase transfer agent is one of decisive factors to improve reaction rate. Usually, quaternary ammonium salt containing 15-25 carbon atoms has good catalytic effect ${ }^{25}$ and the amount of salt account for $1-5 \%$ of reactant (mole fraction). Tetrabutyl-ammonium bromide was chosen as the phase transfer agent in this investigation for its approximate symmetry molecular structure. From experiment No.2 
and No.4, it can be seen that when the amount of tetrabutyl-ammonium bromide was $4.9 \%$, the yield was higher under the same conditions.

Generally speaking, all solvents used in phase transfer catalytic reaction are nonpolar or little polar, such as benzene, toluene, THF, dichloromethane, and dichloroethane, etc. Dichloromethane is the most commonly used solvent. Comparing experiment No.2 and No.6, it is found that the yield was increased when dichloromethane was used.

In the synthesis of TPAPB, the alkali liquor was another critical factor affecting the yield. From Table I, the yield of experiment No.8 (72.3\%) was higher than that of No.7 (49.5\%), and the yield of experiment No.2 (95.3\%) was higher than that of No.8 (72.3\%), indicating that $\mathrm{NaOH}$ was an optimal alkali liquor.

\section{Purification and characterization of TPAPB}

Thin layer chromatography and column chromatography were used for the purification in this study. Ethyl acetate/dichloromethane blended solvent with the volume ratio of 1:8 was used as developing solvent. The yield of purified product was $60 \%$. The melting point of TPAPB was $125^{\circ} \mathrm{C}$, determined by the X-5 microscopic melting point apparatus.

Purified TPAPB can be verified from the spectra analysis of FT-IR and ${ }^{1} \mathrm{H}-\mathrm{NMR}$ results: ${ }^{1} \mathrm{H}-\mathrm{NMR}: \delta(\mathrm{ppm}): 2.25(\mathrm{~s}, 4 \mathrm{H}, \equiv \mathrm{CH}), 4.12\left(\mathrm{~s}, 8 \mathrm{H},-\mathrm{CH}_{2^{-}}\right)$. FT-IR: $\left(\mathrm{KBr}, \mathrm{cm}^{-1}\right)$ 
$\equiv \mathrm{C}-\mathrm{H}: 3276, \mathrm{C} \equiv \mathrm{C}: 2109$. The FT-IR and ${ }^{\mathrm{l} H}$-NMR spectra were shown in Figure 1 and 2, respectively.

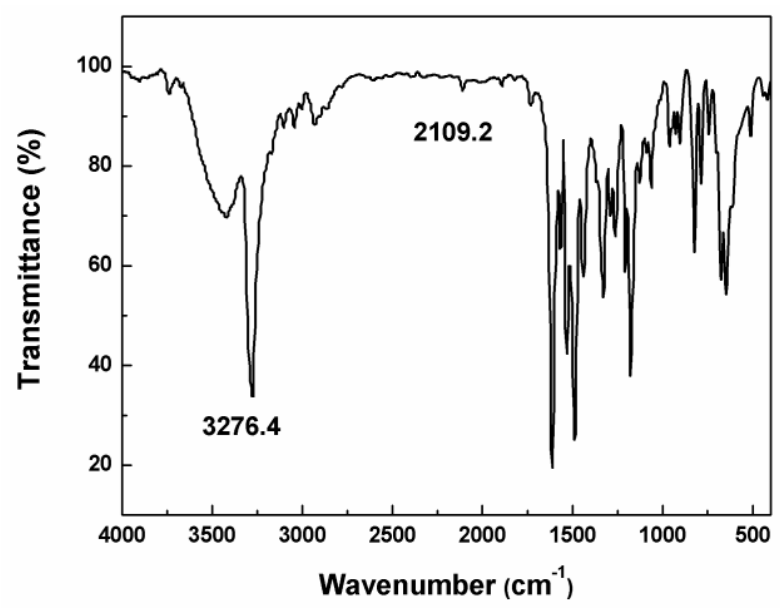

Figure 1. The FT-IR spectrum of TPAPB

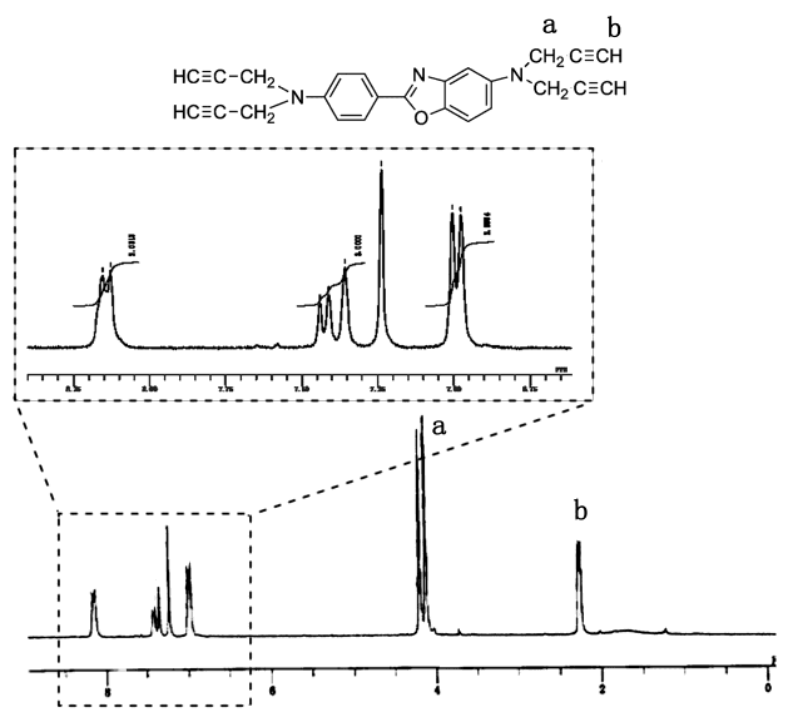


Figure 2. The ${ }^{1} \mathrm{H}-\mathrm{NMR}$ spectrum of TPAPB

\section{Solubility of TPAPB}

The solubility of TPAPB was shown in Table II. The compound can be dissolved in many common solvents, such as acetone, dichloromethane, and Dichloroethane, etc. The result indicated that the propargyl groups incorporated into 5-amino-2-(p-aminophenyl) benzoxazole can improve the solubility of the product. Therefore, it is suitable for solution prepreg preparation in composite fabrication.

Table II. Solubility of TPAPB

\begin{tabular}{cccccccc}
\hline Solvent & Acetone & $\mathrm{CH}_{2} \mathrm{Cl}_{2}$ & $\mathrm{CHCl}_{3}$ & DMF & Toluene & Ether & Ethanol \\
\hline Solubility & ++ & ++ & ++ & ++ & +- & +- & -- \\
\hline
\end{tabular}

\section{Rheological behavior of TPAPB}

The viscosity of the TPAPB was measured at temperatures ranging from melting point $\left(125{ }^{\circ} \mathrm{C}\right)$ to $257^{\circ} \mathrm{C}$ (heating rate $=5{ }^{\circ} \mathrm{C} / \mathrm{min}$ ) by an Advanced Rheometric Expansion System rheometer. The rheological curvet was shown in Figure 3.

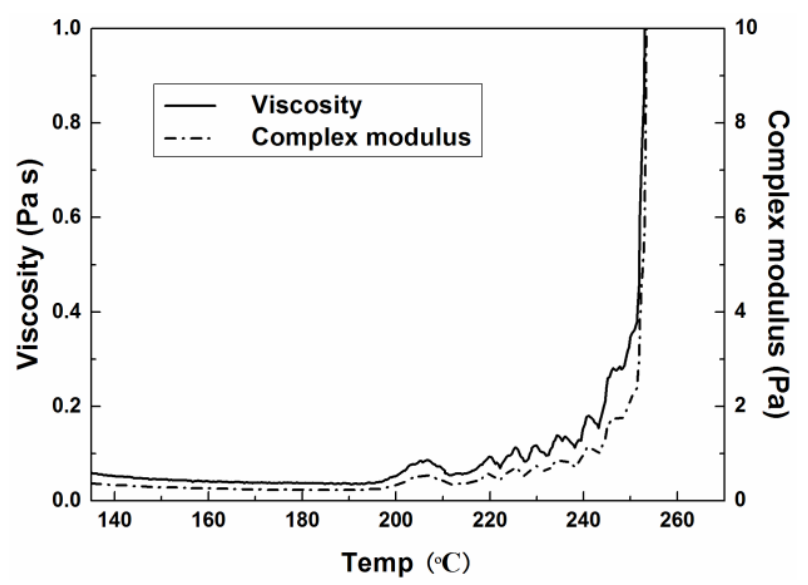


Figure 3. Viscosity and complex modulus curves of TPAPB

The new synthesized compound, TPAPB, melt at about $125^{\circ} \mathrm{C}$. The viscosity was steadily below $0.1 \mathrm{~Pa} \cdot \mathrm{s}$ in the range of $130-200{ }^{\circ} \mathrm{C}$, and the viscosity increased quickly with temperature over $200{ }^{\circ} \mathrm{C}$. A broad temperature window from $130{ }^{\circ} \mathrm{C}$ to $200{ }^{\circ} \mathrm{C}$ with low viscosity was suitable for resin transfer molding (RTM) process and the fabrication of thermosetting composite materials.

\section{Cure behavior analysis}

The cure of TPAPB is thermally activated, and both the polymerization and post cure proceed with no generation of by-products. The reaction behavior of the curing process was systematically studied. The non-isothermal differential scanning calorimetry (DSC) test was used to study the curing mechanism. The phenomenological kinetics of cure can be generally described as Eq. (1):

$$
\frac{d \alpha}{d t}=\mathrm{K}(T) f(\alpha)=A \exp \left(-E_{a} / R T\right) f(\alpha)
$$

where $K(T)$ is reaction rate constant dependent on temperature, $f(\alpha)$ is the function of conversion $(\alpha)$ determined by the cure mechanism, $A$ and $E_{\mathrm{a}}$ represent pre-exponential factor and activation energy of the Arrhenius equation respectively, $\mathrm{R}$ is the universal gas constant $\left(8.3145 \mathrm{~J} \cdot \mathrm{mol}^{-1} \cdot \mathrm{K}^{-1}\right)$, and $\mathrm{T}$ is absolute temperature. 


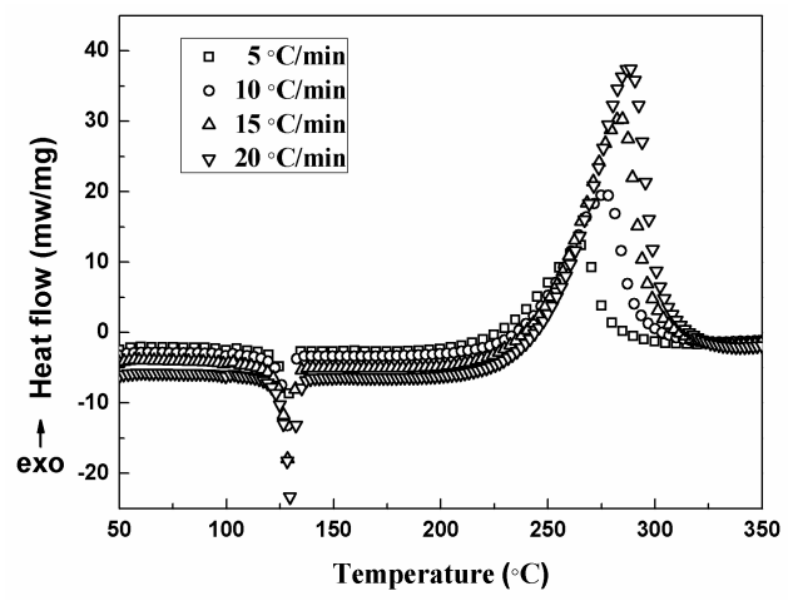

Figure 4. DSC curves of monomer TPAPB at different scanning rates

The kinetic parameters, activation energy and pre-exponential factor, were evaluated by Kissinger, Ozawa methods..$^{23,26,27}$ The order of reaction (n) was calculated by Kissinger equation and Crane equation. ${ }^{28}$ The dynamic DSC curves for TPAPB in the range of $25-350{ }^{\circ} \mathrm{C}$ at the heating rates of $5,10,15,20{ }^{\circ} \mathrm{C} / \mathrm{min}$ were presented in Figure 4. The data obtained from the curves were used to calculate the kinetic parameters. The results indicated that for calculating the activation energy value, both Kissinger and Ozawa's methods gave fairly close results: 145.91 and $147.43 \mathrm{~kJ} \cdot \mathrm{mol}^{-1}$, respectively. The kinetic parameters were summarized in Table III.

Table III. Kinetic parameters of the cure reaction

\begin{tabular}{cccc}
\hline parameter & $\mathrm{Ea}^{\mathrm{a}}\left(\mathrm{kJ} \cdot \mathrm{mol}^{-1}\right)$ & $\mathrm{A}\left(\mathrm{min}^{-1}\right)$ & $\mathrm{n}$ \\
\hline value & 145.91 & $4.20 \times 10^{13}$ & 0.94 \\
\hline
\end{tabular}

a Obtained by Kissinger method.

Substituting the kinetic parameters into Eq. (1), the mathematic model of curing processes of TPAPB was obtained, as described in Eq. (2). 


$$
\frac{d \alpha}{d t}=4.20 \times 10^{13} \exp \left(-1.76 \times 10^{4} / T\right)(1-\alpha)^{0.94}
$$

By integrating the above kinetic equation (Eq. (2)), the function of the three variables $(\alpha, t, T)$ was derived in Eq. (3). The conversion-time relationships of the TPAPB for isothermal curing at 25, 40, 150, 200 and $240{ }^{\circ} \mathrm{C}$ were plotted in Figure 5. The figure showed that the compound cured in a relatively short period of time upon $200{ }^{\circ} \mathrm{C}$ but it kept extremely low conversion rate within a fairly long time when the temperature was below $40{ }^{\circ} \mathrm{C}$. Considerable conversion did not occur at $25{ }^{\circ} \mathrm{C}$ after one year. It can be speculated that the newly synthesized compound can be stably stored for an incredibly long period at room temperature.

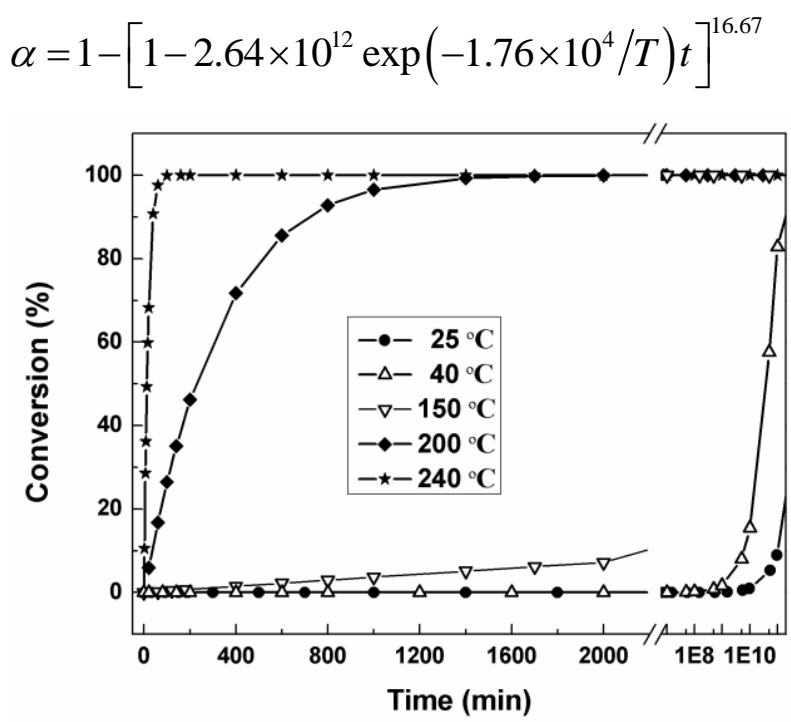


Figure 5. Conversion rate versus time at different curing temperatures: $25^{\circ} \mathrm{C}, 40{ }^{\circ} \mathrm{C}$,

$$
150{ }^{\circ} \mathrm{C}, 200{ }^{\circ} \mathrm{C} \text {, and } 240{ }^{\circ} \mathrm{C}
$$

According to the conversion-time relationship of TPAPB in figure 5, the conversion approached $100 \%$ rapidly within $2 \mathrm{~h}$ at $240{ }^{\circ} \mathrm{C}$. So the curing process could be: $180{ }^{\circ} \mathrm{C} / 1 \mathrm{~h}, 200{ }^{\circ} \mathrm{C} / 2 \mathrm{~h}, 230{ }^{\circ} \mathrm{C} / 2 \mathrm{~h}$ and $250{ }^{\circ} \mathrm{C} / 4 \mathrm{~h}$.

The curing behavior of TPAPB was studied by FT-IR and DSC. The DSC curve was shown in Figure 6. The curing was completed with the end of the curing exothermic effect. The FT-IR spectra were shown in Figure 7. The disappearance of $\equiv \mathrm{C}-\mathrm{H}$ and $\mathrm{C} \equiv \mathrm{C}$ stretching vibrations at 3276 and $2109 \mathrm{~cm}^{-1}$ indicated that propargyl groups had been completely converted during the thermal curing process. Cross-linking reaction involving $\mathrm{C} \equiv \mathrm{C}$ bond might have occurred to form a thermally stable structure. Further study will be needed to clarify the mechanism of the reaction and the resulting thermal stability. The thermal polymerization is believed to proceed through addition reactions between the acetylene groups to form a conjugated polyene, ${ }^{29}$ which then participated in more complex reactions to yield crosslinked structures. Other reactions are also possible such as polycyclotrimerization reaction. ${ }^{30}$ The plausible mechanism of the polymerization of TPAPB was demonstrated in Scheme 3. 


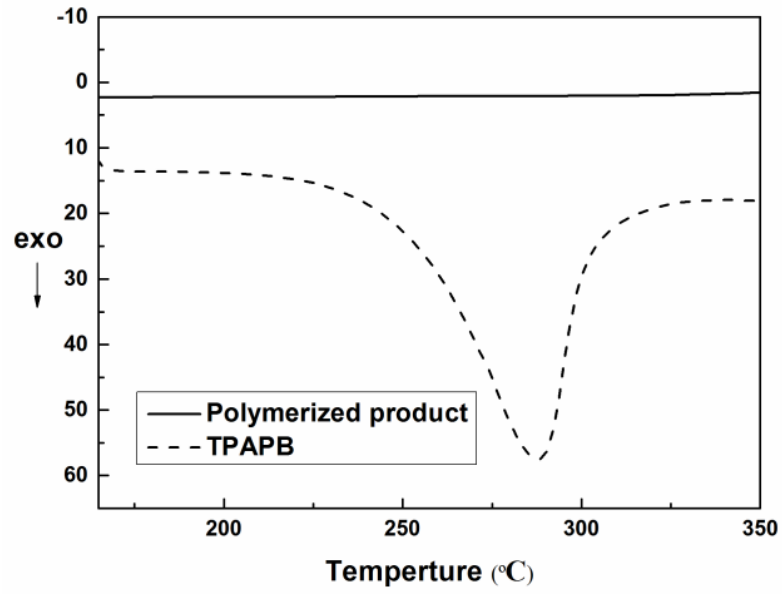

Figure 6. DSC trace of TPAPB and the polymerized product (Ar, heating rate $\left.20{ }^{\circ} \mathrm{C} / \mathrm{min}\right)$

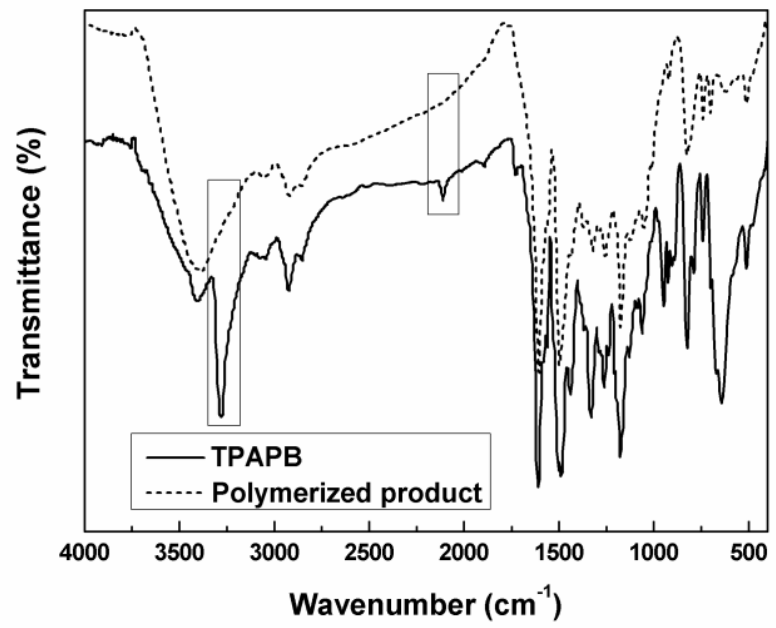


Figure 7. FT-IR spectra of TPAPB and its polymerized product

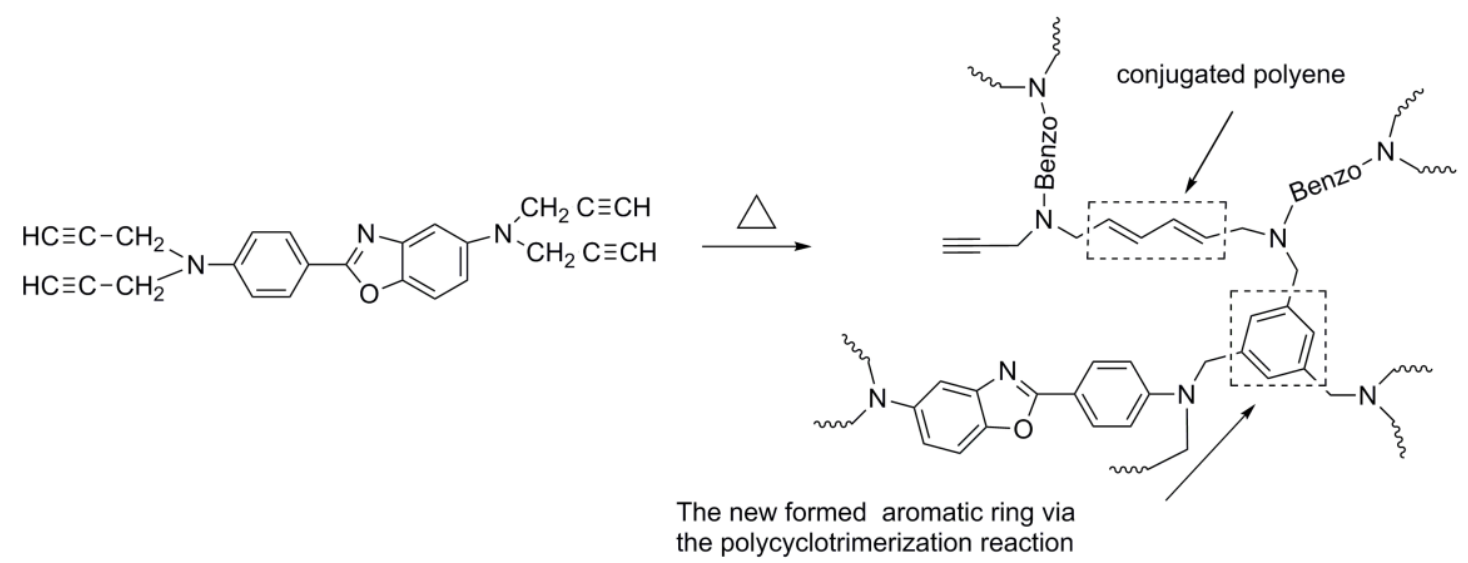

Scheme 3. Plausible mechanism of the polymerization of TPAPB

\section{Thermal properties of cured TPAPB}

Thermogravimetric analysis (TGA) and differential scanning calorimetry (DSC) under argon were used to study the thermal properties of TPAPB. The DSC curve and TGA curve were shown in Figure 8 and Figure 9, respectively.

The results showed that the glass transition temperature $\left(T_{g}\right)$ of cured TPAPB was $359{ }^{\circ} \mathrm{C}$ and there was no exothermal peak in DSC curve, exhibiting good thermal stability. 


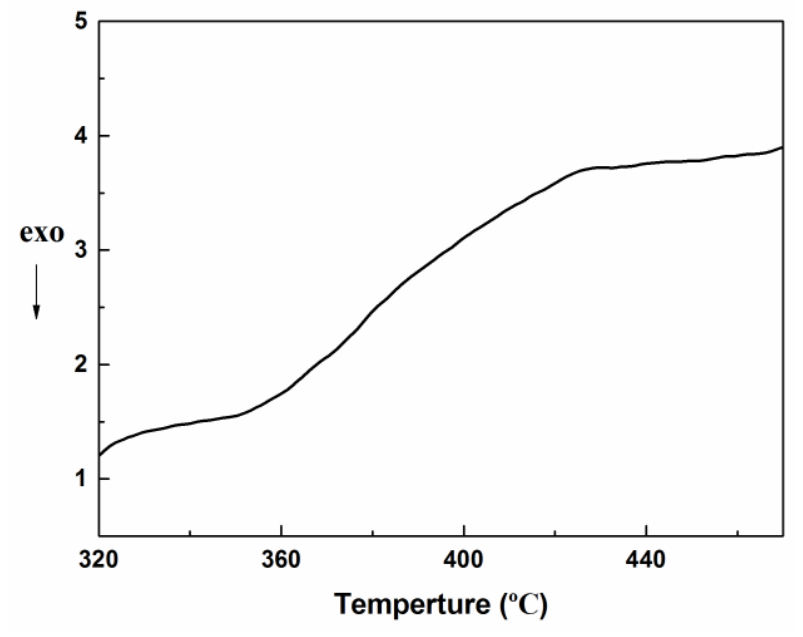

Figure 8. DSC of the cured TPAPB (Ar, heating rate $20{ }^{\circ} \mathrm{C} / \mathrm{min}$ )

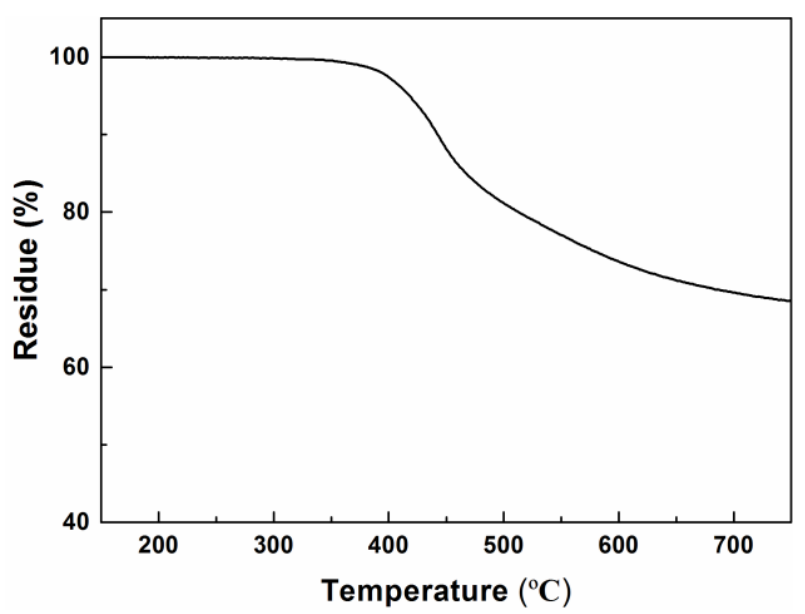

Figure 9. TGA result of the cured TPAPB (Ar, heating rate $20^{\circ} \mathrm{C} / \mathrm{min}$ )

$\mathrm{T}_{d 5}$ (temperature of $5 \%$ weight loss, determined by the TGA trace, under argon) was $418{ }^{\circ} \mathrm{C}$, and the residue (under argon) at $700{ }^{\circ} \mathrm{C}$ was $70 \%$. These values were much higher than those of the bis-propargyl ether resins, e.g. Dipropargyl ether of bisphenol A (DPEBA), of which residue at $700{ }^{\circ} \mathrm{C}$ was $57 \% .{ }^{31}$ From these results, it can be drawn 
that the benzoxazole and propargyl structures can increase the heat resistance and thermal stability of the resin, mainly because they are rigid groups and thermally stable structure might be formed by cross-linking reaction involving $\mathrm{C} \equiv \mathrm{C}$ bond.

\section{Conclusions}

N, N, N', N'-tetra propargyl-5-amino- 2-(p-aminophenyl) benzoxazole (TPAPB), a novel propargyl-terminated compound, was proposed and synthesized using phase-transfer catalytic method.

TPAPB can be dissolved in many common solvents, such as acetone, ethyl acetate, and dichloromethane, etc. The solubility and rheological properties of TPAPB, as well as its broad temperature window from $130{ }^{\circ} \mathrm{C}$ to $200{ }^{\circ} \mathrm{C}$ with low viscosity, offered excellent processability for TPAPB to be used as a monomer of thermosetting polymer resin. The curing behavior of TPAPB evaluated by nonisothermal DSC method showed that the apparent activation energies of the cure reaction were $145.9 \mathrm{~kJ} \cdot \mathrm{mol}^{-1}$ and 147.4 $\mathrm{kJ} \cdot \mathrm{mol}^{-1}$ determined by Kissinger and Ozawa methods respectively and that the novel compound possessed extraordinarily long shelf life. $T_{g}$ of TPAPB was $359^{\circ} \mathrm{C}, \mathrm{T}_{d 5}$ (the temperature of $5 \%$ weight loss, under argon) was $418{ }^{\circ} \mathrm{C}$ and the residue at $700{ }^{\circ} \mathrm{C}$ under argon was $70 \%$. The polymerized product showed good heat resistance and thermal stability indicating that the resin has good potential to be used as thermal resistant polymer matrix for advanced composite applications. 


\section{Acknowledgements}

This work was funded by the Aerospace Innovation Foundation of China. 


\section{References}

1. Li Q, Zhou Y, Hang XD, et al. Synthesis and characterization of a novel arylacetylene oligomer containing POSS units in main chains. Eur Polym J 2008; 44: $2538-2544$.

2. Huang JX, Du W, Zhang J, et al. Study on the copolymers of silicon-containing arylacetylene resin and acetylene-functional benzoxazine. Polym Bull 2009; 62: $127-138$.

3. Kimura H, Ohtsuka K, Matsumoto A, et al. Synthesis and characterization of phenylethynylcarbonyl terminated novel thermosetting imide compound. Express Polym Lett 2013; 7: 161-171.

4. Yang Y, Fan L, Qu XM, et al. Fluorinated phenylethynyl-terminated imide oligomers with reduced melt viscosity and enhanced melt stability. Polymer 2011; 52: $138-148$.

5. Hergenrother PM. The use, design, synthesis, and properties of high performance/high temperature polymers. High Perform Polym 2002; 15: 3-45.

6. Agag $\mathrm{T}$ and Takeichi $\mathrm{T}$. Novel benzoxazine monomers containing p-phenyl propargyl ether: polymerization of monomers and properties of polybenzoxazines. Macromolecules 2001; 34: 7257-7263. 
7. Agag $\mathrm{T}$ and Takeichi $\mathrm{T}$. Preparation, characterization, and polymerization of maleimidobenzoxazine monomers as a novel class of thermosetting resins. J Polym Sci, Part A: Polym Chem 2006; 44: 1424-1435.

8. Ding YZ, Hu C, Guo X, et al. Structure and Mechanical Properties of Novel Composites Based on Glycidyl Azide Polymer and Propargyl-Terminated Polybutadiene as Potential Binder of Solid Propellant. J Appl Polym Sci 2014; 131: 40007-40014.

9. He XZ, Yang XM and Jabbari E. Combined Effect of Osteopontin and BMP-2 Derived Peptides Grafted to an Adhesive Hydrogel on Osteogenic and Vasculogenic Differentiation of Marrow Stromal Cells. Langmuir 2012; 28: 5387-5397.

10. Kawanami T, Kawakami I, Sakamoto H, et al. Super environment-friendly electrodeposition paint. Prog Org Coat 2000; 40: 61-62.

11. Mehdipour-Ataei S and Gharehkhani E. Preparation of novel pyridine-based poly (ether amide) s via three different routes and investigation of their properties. High Perform Polym 2013; 25: 778-789.

12. Hu XD, Jenkins SE, Min BG, et al. Rigid-rod polymers: Synthesis, processing, simulation, structure, and properties. Macromol Mater Eng 2003; 288: 823-843.

13. Yang $\mathrm{P}$ and $\mathrm{Gu} \mathrm{Y}$. Synthesis of a novel benzoxazine-containing benzoxazole structure and its high performance thermoset. J Appl Polym Sci 2012; 124: 2415-2422. 
14. Li K, Luo LB, Huang JY, et al. Enhancing mechanical properties of aromatic polyamide fibers containing benzimidazole units via temporarily suppressing hydrogen bonding and crystallization. J Appl Polym Sci 2015; 132: 42482-42491.

15. Wang $\mathrm{Y}, \mathrm{Yu} \mathrm{JR}, \mathrm{Zhu} \mathrm{J}$, et al. Hyperbranched polybenzoxazoles incorporated polybenzoxazoles for high-performance and low-K materials. J Polym Sci, Part A: Polym Chem 2015; 54: 1623-1632.

16. Intemann JJ, Hellerich ES, Tlach BC, et al. Altering the Conjugation Pathway for Improved Performance of Benzobisoxazole-Based Polymer Guest Emitters in Polymer Light-Emitting Diodes. Macromolecules 2012; 45: 6888-6897.

17. Yang G, Zhou CG and Li B. Novel propargylether-terminated monomers containing pyridine and phenyl pendent group: Synthesis, cure, and properties. J Appl Polym Sci 2014; 131: 40469-40476.

18. Dhanalakshmi JP, Alam S and Vijayakumar CT. High temperature matrix resins based on bispropargyl ethers-part 1 Effect of copper salts on the thermal polymerisation of bispropargylether of bisphenol-A and the thermal stability of these polymers. High Perform Polym 2013; 25: 416-426.

19. Luo LB, Zheng YX, Huang JY, et al. High-performance copoly (benzimidazole-benzoxazole-imide) fibers: Fabrication, structure, and properties. $J$ Appl Polym Sci 2015; 132: 42001-42009. 
20. Yang ZH, Chen Y, Wang QH, et al. High performance multiple-shape memory behaviors of Poly (benzoxazole-co-imide) s. Polymer 2016; 88: 19-28.

21. Wu J, Wang Y, Yu JR, et al. Synthesis of hyperbranched polybenzoxazoles and their molecular composites with epoxy resins. J Appl Polym Sci 2015; 132: 41942-41950.

22. Yang G, Li B, Zhang $\mathrm{MN}$, et al. High heat-resistant linear propargyl ether-terminated polymers containing $\mathrm{Si}-\mathrm{H}$ group: Synthesis, characterization, and properties. High Perform Polym 2013; 26: 290-297.

23. Yang G, Yuan ZH, Yang ZY, et al. Nonisothermal Curing Kinetics of a Novel Polymer Containing Phenylsilylene and Propargyl-Hexafluorobisphenol A Units. $J$ Appl Polym Sci 2013; 127: 3178-3185.

24. Preston J, DeWinter WF, Fofferbert WL, et al. Heterocyclic intermediates for the preparation of thermally stable polymers. III. Unsymmetrical benzoxazole, benzothiazole and benzimidazole diamines. J Heterocycl Chem 1969; 6: 119-121.

25. Hashimoto $\mathrm{T}$ and Maruoka K. Recent development and application of chiral phase-transfer catalysts. Chem Rev 2007; 107: 5656-5682.

26. Kissinger HE. Reaction Kinetics in Differential Thermal Analysis. Anal Chem 1957; 29: $1702-1706$.

27. Ozawa T. Kinetic analysis of derivative curves in thermal analysis. J Therm Anal 1970; 2: 301-324. 
28. Crane LW, Dynes PJ and Kaelble DH. Analysis of curing kinetics in polymer composites. J Polym Sci Polym Lett Ed 1973; 11: 533-540.

29. Liu JZ, Lam JWY and Tang BZ. Acetylenic Polymers: Syntheses, Structures, and Functions. Chem Rev 2009; 109: 5799-5867.

30. Zheng RH, Haussler M, Dong HC, et al. Synthesis, structural characterization, and thermal and optical properties of hyperbranched poly(aminoarylene)s. Macromolecules 2006; 39: 7973-7984.

31. Nair CPR, Bindu RL, Krishnan K, et al. Bis propargyl ether resins: synthesis and structure-thermal property correlations. Eur Polym J 1999; 35: 235-246. 